

RESEARCH ARTICLE

\title{
BREAST CANCER PATIENT'S EXPERIENCE OF POST-TRAUMATIC GROWTH: RELATIONSHIP WITH COPING STRATEGIES AND SOCIAL SUPPORT.
}

\section{Shams Un Nisa ${ }^{1}$ and Touseef Rizvi' .}

1. Contractual Lecturer, Department of Psychology, University of Kashmir, Hazratbal, Srinagar, 190006.

2. Sr. Asst. Professor, Department of Psychology, University of Kashmir, Hazratbal, Srinagar, 190006.

\section{Manuscript Info}

Manuscript History

Received: 23 August 2017

Final Accepted: 25 September 2017

Published: October 2017

Key words:-

Breast cancer, Coping, Social Support, Post-traumatic Growth.

\begin{abstract}
Survival rates in breast cancer patients have improved due to increased options for early diagnosis and better treatment methods. The diagnosis of breast cancer affects individuals both positively and negatively in physical, psychological and social dimensions. However, the negative effect of trauma has been well documented in literature, with limited data on positive effects. Nevertheless, the identification of positive changes and defining its determinants is important in supporting and strengthening posttraumatic growth in this group. This study investigated the relationship between coping strategies, social support and post-traumatic growth. The main research design was crosssectional and responses were taken from 176 participants who have been diagnosed with breast cancer. Participants were taken from Department of Radiation Oncology, Government Medical College and Associated Hospitals, Karan Nagar, Srinagar, Department of Oncology, Florence Hospital, Chanapora, Srinagar, Department of Oncology, Noora Hospital Srinagar and Cancer Society of Kashmir (NGO), Lal Nagar, Chanapora, Srinagar, Kashmir, in the age range of 25-70 years (mean age $=46.6, \mathrm{SD}=10.9$ ). Patients completed the sample survey packets comprised of "Brief COPE, (Carver, 1997)", "MultiDimensional Scale of Perceived Social Support (Zimet, Dahlem, Zimet \& Farley, 1988)" and "Post Traumatic Growth Inventory-Short-Form (Cann, Calhoun, Tedeschi, Taku, Vishnevsky, Triplett \& Danhauer, 2010)" and demographic data sheet. Bivariate analysis revealed that Active-adaptive coping and Social Support (Family, Friends and Significant other) are significantly correlated with post-traumatic growth. Multiple regression analysis was applied to investigate the degree to which post-traumatic is influenced by Coping and Social Support. Results revealed that Active-adaptive coping and support from Family and Significant other significantly influence post-traumatic growth.
\end{abstract}

Copy Right, IJAR, 2017,. All rights reserved.

\section{Introduction:-}

Breast cancer is a highly stressful and threatening life event (Ben-Zur, Gilbar, \& Lev, 2001). The patient's life is placed in jeopardy by the disease and the fact that surgical intervention for the disease is disfiguring adds to this

Corresponding Author:- Shams Un Nisa. 190006. 
distress. Women who have been surgically treated for breast cancer often experience important life changes such as insomnia, loss of appetite and difficulty in returning to usual household and employment responsibilities. The diagnosis also holds further implications for social relations and psychological well-being. All these changes can cause psychological and emotional distress, most commonly depression, anxiety and hopelessness. On the other hand, breast cancer can also form a turning point which can unfold to contribute to positive changes in the survivors' life. Many survivors of breast cancer express perceptions of benefit or stress-related growth related to their experiences (Cordova, Cunnigham, Carlson, \& Andrykowski, 2001; Weiss, 2004). Sears et al. (2003) found that $83 \%$ of women with early-stage breast cancer report positive consequences from their cancer experience. Some of the frequently reported positive changes include altered priorities, better relationships with others, a greater sense of purpose, and a greater appreciation of one-self and one's life (Dow, Ferrell , Haberman , \& Eaton, 1999; Schroevers, Ranchor, \& Sanderman 2006). A number of factors have been found to influence the process of posttraumatic growth. It is acknowledged that using adequate and adaptive coping strategies produces growth (Armeli, Gunthert \& Cohen, 2001). It was found that there is a relationship between posttraumatic growth and different coping strategies such as positive reinterpretation (reframing/reappraisal) (Park, Cohen \& Murch, 1996; Schroevers \& Teo, 2008; Siegel, Schrimchaw \& Pretter, 2005; Thornton \& Perez, 2006; Urcuyo, Boyers, Carver \& Antoni,2005), religious coping (Koenig, Pargament \& Nielsen, 1998; Park, Cohen \& Murch, 1996; Urcuyo, Boyers, Carver \& Antoni, 2005), acceptance coping (Schulz \& Mohammed, 2004; Urcuyo, Boyers, Carver \& Antoni, 2005), substance use coping (Urcuyo, Boyers, Carver \& Antoni, 2005), emotional social support coping (Park, Cohen \& Murch, 1996), instrumental support (Schroevers \& Teo, 2008), avoidance coping (Widows, Jacobsen, Booth-Jones \& Fields, 2005), active coping (Collins, Taylor \& Skokan, 1990; Urcuyo, Boyers, Carver \& Antoni, 2005) and problem-focused coping (Dirik \& Karanci, 2008; Sheikh, 2008). Problem-focused coping strategies involve attending to problem directly and attending to actual person situation relationship and has been found to be related to post-traumatic growth (Dirik \& Karanci, 2008). This coping strategy is asserted to promote growth, because active involvement in problem may lead the person to have enhanced self-efficacy and self-confidence that may promote growth. Literature supports the relationship between post-traumatic growth and problem focussed coping strategies. A positive relation was found between post traumatic growth and problem focussed coping (Kesimci, Goral \& Gencoz, 2005). Similarly, Armeli, Gunthert and Cohen (2001) stated that individuals using problem focused coping experience more growth.

Research suggests that social support also increases the probability of developing positive changes after trauma. This refers to both the availability of support and perceived or obtained support. Emotional support represents a particularly important type of help, especially if obtained immediately after an experienced traumatic event. The possibility of sharing thoughts and feelings and expressing emotions supports the processing of trauma and raises the chances for posttraumatic growth (Tedeschi \& Calhoun, 1996). Harvey, Barnett and Overstreet (2004) emphasized that the possibility of sharing emotions with other people is a key factor in the process of coping with trauma. Therefore, the availability of a support network, including formal groups offering help to individuals in need, is of vital importance. This type of support promotes positive changes even in those traumatized persons who do not seek help actively. Tedeschi \& Calhoun (2004) suggested that the important role of support is associated with the fact that offered support mobilizes persons experiencing trauma to active, problem-oriented rumination (deliberate rumination). In contrast to intrusive rumination, this type of rumination has defined objectives and leads to adaptive reinterpretation of cognitive schemas regarding the world and the self and establishing a new, more realistic vision of reality, which in turn promotes the development of positive changes. Support from persons who have experienced or still experience similar trauma is vitally important, albeit difficult. Self-comparison with persons who are in even more difficult situations and still cope with trauma can constitute a very important and supportive source of power. This was emphasized by Taylor (1983) in her concept of cognitive adaptation.

The central focus of this paper was the relationship of coping strategies and social support with post-traumatic growth in cancer patients. We expected positive changes to be significantly related to coping strategies and social support. Second we also examined the influence of coping strategies and social support on post-traumatic growth.

\section{Method:-}

\section{Sample and Procedure:-}

Participants were selected with the assistance from Department of Radiation Oncology, Government Medical College, Karan Nagar, Srinagar and Department of Oncology, Noora Hospital, Zainakote, Srinagar. A total of 176 patients were selected for the study. The inclusion and exclusion criteria for sample group were as follows: (1) 
Patients having definite diagnosis of breast cancer. (2) At least six months' time duration since the diagnosis of the disease. (3) Patients providing informed consent. (4) Patients with other physical or psychological problems were excluded from the study. (5) Patients with history of metastases and critically ill patients were excluded from this study (6) Patients who had no knowledge of their diagnosis were also excluded from this study (7) Lack of patient's consent to participate in the study was another exclusion criterion. Researcher explained the aims and the procedure of the study to the authorities and their consent for conducting the study was obtained. Subsequently patients who met the inclusion criteria set by the researcher were chosen. Some of the patients were under treatment whereas others were on follow-up appointment at the hospital. The data was collected individually from the participants. The researcher introduced herself to the patients and explained the aim and purpose of the study. Confidentiality was ensured to the participants and they were told that they could stop and discontinue at any time of the study. Verbal consent was taken from each of the participants. The scales were applied by the researcher in face to face format. For all the scales necessary instructions were given and researcher helped the participants in marking their answers if they experienced difficulties. For illiterate patients the scales were administered by the researcher providing all help in understanding the questions and marking the answers. Data was collected from both out-patient department (OPD) as well as in-patient department (IPD).

\section{Measures:- \\ Post-Traumatic Growth:-}

Positive changes were measured with Post-traumatic Growth Inventory Short Form (Cann et. al. 2010) which has been designed to assess the positive legacy of traumatic events and major crisis and stressors of life. PTGI-SF has 10 items assessing five dimensions of positive growth with two items assessing one dimension. It is a 6-point Likert scale with response categories ranging from 0 as "I did not experience this change as a result of this crisis" to 5 as "I experienced this change to a very great degree as a result of my crisis" and higher scores represent greater perceived posttraumatic growth. There is enough empirical evidence indicating the good psychometric properties of PTGI-SF, with Cronbach alpha ranging from PTGI-Total (0.86), Relating to others (0.68), New Possibilities (0.77), Personal Strength (0.74), Spiritual Change (0.80) and Appreciation of Life (0.68). (Cann, Calhoun, Tedeschi, Taku, Vishnevsky, Triplett \& Danhauer, 2010). Cronbach's $\alpha$-coefficient was found to be 0.71 for this study.

\section{Coping Strategies:-}

Coping was assessed using Brief COPE (Carver, 1997). This scale has been designed to assess broad range of coping responses among adults for all diseases. It consists of 28 items rated on a 4-point Likert scale from "I haven't been doing this at all" to "I have been doing this a lot". These items are divided into fourteen sub-scales. Each of the 14 sub-scales is comprised of 2 items, total scores on each sub-scale range from 2 (minimum) to 8 (maximum). Higher scores indicate increased utilization of that specific coping strategy. Empirical evidence exists indicating the sound psychometric properties of the scale. Internal reliabilities for the 14 subscales range from $\alpha=$ 0.57-0.90 (Carver, 1997). The criterion-related validity has been established by correlating the Brief Cope with Brief Psychiatric Rating Scale (BPRS) measuring dissimilar construct $(r=-0.44)$ and positively associated with positive social functioning (SAS) $(r=0.33)$ (Meyer, 2001). Though COPE sub-scales are intended to be used independently research has suggested that sub-scales of denial, substance abuse, self-blame, behavioural disengagement, self-distraction capture avoidant coping and the sub-scales of active-coping, use of emotional support, use of instrumental support, positive reframing, planning, humour, acceptance and religion best capture approach or adaptive coping (Kershaw, Northouse, Kritpracha, Schafenacker \& Mood, 2004; Oxman, Hegel, Hull \& Dietrich, 2008; Schnider, Ilhai \& Gray 2007). To have a more practical measure one original sub-scale of substance abuse was discarded due to cultural issues. The score of active-adaptive coping was computed by adding the subscales of Active Coping, Use of Emotional Support, Use of Instrumental Support, Positive Reframing, Planning, Humour, Acceptance, Religion, Venting and Self-distraction. The score of avoidance coping was computed by adding the sub-scales of Denial, Self-blame and Behavioural Disengagement (Carver, Scheier \& Weintraub, 1989; Danheur et al., 2013). The authors found the Cronbach's $\alpha$-coefficient of 0.74 for active-adaptive coping and 0.69 for avoidance coping in this study.

\section{Social Support:-}

For the assessment of social support Multi-Dimensional Scale of Perceived Social Support (Zimet, Dahlem, Zimet \& Farley, 1988) was used. It consists of 12 items which are rated on a 7-point Likert scale. These 12 items assess support from three sources "Friends", "Family" and "Significant Other". There is enough empirical evidence indicating the sound psychometric properties of MSPSS. Coefficient alpha ranged from.81 to.90 for Family subscale, from .90 to .94 for the Friends sub-scale, from .83 to .98 for Significant other sub-scale and .84 to .92 for the 
scale as a whole (Zimet, Powell, Farley, Werkman \& Berkoff, 1990). In this study Cronbach's $\alpha$-coefficient was 0.71 for friends sub-scale, 0.89 for family sub-scale, and 0.91 for significant other sub-scale.

\section{Statistical Analysis:-}

Descriptive analyses were performed and means and standard deviations will be presented. Concerning the relationship between coping strategies, social support and post-traumatic growth we used Pearson's correlation $(\mathrm{p} \leq 0.05)$. Next we used the multiple regression analysis to examine the influence of coping strategies and social support on post-traumatic growth.

\section{Results:-}

\section{Descriptives and Correlations:-}

Table 1 presents the means, standard deviations and ranges of the study variables. In table 2 and table 3 the relationships among study variables are shown. Regarding the relationship between study variables we found a significant and positive relationship of active-adaptive coping $(\mathrm{r}=.38, \mathrm{p}<0.01)$, social support from friends $(\mathrm{r}=.29$, $\mathrm{p}<0.01)$, family $(\mathrm{r}=.15, \mathrm{p}<0.05)$, significant other $(\mathrm{r}=.31, \mathrm{p}<0.01)$ with post-traumatic growth.

Table 1:- Descriptives of study variables

\begin{tabular}{|c|c|c|c|}
\hline Study Variables & $M$ & SD & Range \\
\hline Active-adaptive Coping & 62.59 & 6.41 & $40-78$ \\
\hline Avoidance Coping & 11.55 & 2.77 & $8-20$ \\
\hline Support from Family & 24.53 & 2.67 & $16-28$ \\
\hline Support from Friends & 16.07 & 4.38 & $4-28$ \\
\hline Support from Significant Other & 24.63 & 3.90 & $5-28$ \\
\hline Post-traumatic Growth & 37.18 & 5.39 & $23-49$ \\
\hline
\end{tabular}

Table 2:- Pearson's Correlation between Coping Strategies and Post-traumatic growth

\begin{tabular}{|c|c|}
\hline Coping & Post-traumatic Growth \\
\hline Active-adaptive Coping & $.38^{* *}$ \\
\hline Avoidance Coping & $-.05^{\text {NS }}$ \\
\hline
\end{tabular}

$* * \mathrm{p} \leq 0.01 ; \mathrm{NS}=$ Insignificant

Table 3:- Pearson's Correlation between Social Support and Post-traumatic growth

\begin{tabular}{|c|c|}
\hline Social Support & Post-traumatic Growth \\
\hline Family & $.29^{* *}$ \\
\hline Friends & $.15^{*}$ \\
\hline Significant Other & $.31^{* *}$ \\
\hline Total & $.34 * *$ \\
\hline
\end{tabular}

$* * \mathrm{p} \leq 0.01 ; \mathrm{NS}=$ Insignificant

Influence of Coping Strategies on Post-Traumatic Growth:-

Multiple regression analysis was applied to find out whether active-adaptive and avoidance coping strategies significantly influence post-traumatic growth. As can be seen in the Table 4 Active-adaptive coping $(\beta=.39, p<$ $.01)$, could predict $14 \%$ of the variance $\left(R^{2}=.14 ; F(2,173)=15.159, p<.01\right)$ in the model of post-traumatic growth in breast cancer patients. However, Avoidance Coping $(\beta=.03, p=.67)$ was not found to be a significantly influencing post-traumatic growth in the model.

\begin{tabular}{|c|c|c|c|c|c|c|}
\hline Outcome & Predictors & $B$ & $S E B$ & $B$ & $T$ & $p r$ \\
\hline \multirow{3}{*}{ 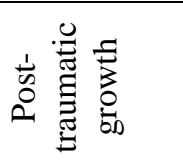 } & Constant & 15.93 & 4.39 & - & $3.67 * *$ & - \\
\hline & $\begin{array}{l}\text { Active-adaptive } \\
\text { Coping }\end{array}$ & .33 & .60 & .39 & $5.46 * *$ & .38 \\
\hline & Avoidance coping & .06 & .14 & .03 & 0.42 & .03 \\
\hline
\end{tabular}

Note: $R^{2}=.14(p \leq .01) ; * * \leq .01$.

\section{Influence of Social Support on Post-Traumatic Growth:-}

To examine the influence of social support on post-traumatic growth multiple regression analysis was applied. As can be seen from the Table 5 Support from family $(\beta=.18, p<.05)$ and Support from significant other $(\beta=.24, p<$ $.01)$ could predict $13 \%$ of the variance $\left(R^{2}=.13 ; F(3,172)=19.04, p<.01\right)$ in the model of post-traumatic growth 
in breast cancer patients. However, Support from friends $(\beta=.83, p=.40)$ was not found to be a significantly influencing post-traumatic growth.

\begin{tabular}{|c|c|c|c|c|c|c|}
\hline Outcome & Predictors & $B$ & $S E B$ & $\beta$ & $t$ & $p r$ \\
\hline \multirow{4}{*}{ 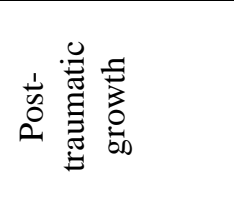 } & Constant & 18.92 & 3.72 & - & $5.08 * *$ & - \\
\hline & Support from Family & .36 & .16 & .18 & $2.23 * *$ & .16 \\
\hline & Support from Friends & .08 & .09 & .06 & 0.83 & .06 \\
\hline & $\begin{array}{l}\text { Support from Sig. } \\
\text { Other }\end{array}$ & .33 & .11 & .24 & $3.17 * *$ & .22 \\
\hline
\end{tabular}

Note: $R^{2}=.13(p \leq .01) ; * * p \leq .01$.

\section{Discussion:-}

This study focussed on the experience of post-traumatic growth in breast cancer patients due to illness. The finding that active-adaptive coping is significantly related to post-traumatic growth is in line with previous studies (Sears, Stanton \& Danoff-Burg, 2004). Health care professionals can utilize cognitive and mindfulness-based techniques so that patients can be assisted to recognize and acknowledge both positive and negative changes in their lives since the traditional cognitive behavioural therapies such as coping skills training, cognitive restructuring etc. have already proved useful and highly effective for managing the pain and distress associated with cancer (Tatrow \& Montgomery, 2006). Consistent with the previous literature this study found avoidant coping to be unrelated to growth (Ho, Chan \& Ho, 2004; Urcuyo, Boyers, Carver \& Antoni (2005). For clinicians and health care professionals this means that instead of reducing avoidant coping strategies post-traumatic growth can be effectively enhanced by stimulating the use of active-adaptive and approach related coping strategies. The current study found social support from family, friends and significant other to be significantly and positively related to post-traumatic growth. A number of studies have shown that the availability of social support during and after a traumatic event can reduce levels of depression, anxiety and other mental and physical disorders amongst those exposed to a range of traumatic events (de Zulueta, 2007; Halcomb, Daly, Davidson, Elliott \& Griffiths, 2005; Keane, Marshall \& Taft, 2006; Walsh, 2007). Post-traumatic growth can be influenced by the availability of social support networks in the aftermath of trauma and adversity (Christopher, 2004; Joseph \& Linley, 2005; Tedeschi \& Calhoun, 2004). This is of particular relevance to Asian collectivist cultures that emphasise mutual support among family members and kinships at all times (Markus \& Kitayama, 1991). Post-traumatic growth has also been found to be positively related with social support (Baglama \& Atak, 2015). The finding of this study that support from family and significant other influences post-traumatic growth can have implications for organising and facilitating activities involving family that provide support for the development of autonomy, skills and sense of belonging to the community in women with breast cancer. Patients may also be assisted in their adaptation to breast cancer by combining the strategies to decrease patient's avoidant tendencies with the strategies that stimulate active approach of difficult situations.

When interpreting these results several limitations need to be taken into account. First of all, this study is crosssectional in nature; therefore, the results do not imply causality. This study used only relational design and because the purposive sampling was used there was no random assignment of participants and there was not any experimental manipulation, so it is difficult to infer causality. Cross sectional studies do not fully clarify the relationship between predictors and outcomes. For example, although it is possible that certain coping strategies may lead to post-traumatic growth (as hypothesized in this study), it is also possible that individuals who have experienced growth may employ more adaptive coping strategies. Therefore, predictors and outcomes may be confounded in cross-sectional research. Future studies should be longitudinal instead of cross-sectional and there should be random assignment of participants so that the causal roles of personality traits, coping and social support in post-traumatic growth can be clarified.

Second, many participants answered the questions orally and they might have given socially desirable answers. Third, the results of the current study are applicable only on breast cancer patients. The factors and determinants of PTG may vary in other samples in the context of different nature of traumatic events. Fourth this study is based on a small sample, taken from only one major Oncology Center and two private hospitals, so caution should be exercised in generalizing the results to a larger population due to representativeness issues. The large sample of patients from different hospitals may provide greater generazibility and controlling for other baseline characteristics and situational factors will further validate the findings. 


\section{Source of Funding:-}

The present research has been funded by Indian Council for Social Science Research, New Delhi, India.

\section{Conflict of Interest:-}

There is no conflict of interest for any of the authors of the present study

\section{References:-}

1. Armeli, S., Gunthert, K. C., \& Cohen, L. H. (2001). Stressor appraisals, Coping and post event outcomes: The dimensionality and antecedents of stress related growth. Journal of Social and Clinical Psychology, 20 (3), 366-395.

2. Baglama, B., \& Atak, I.E. (2015). Posttraumatic Growth and Related Factors among Postoperative Breast Cancer Patients. Procedia-Behavioural and Social Sciences, 21, 448-454.

3. Ben-Zur, H., Gilbar, H., \& Lev, S. (2001). Coping with breast cancer: patient, spouse, and dyad models. Psychosom Med., 63(1), 32-39

4. Cann, A., Calhoun, L. G., Tedeschi, R. G., Taku, K., Vishnevsky, T., Triplett, K. N., \& Danhauer, S. C. (2010). A short form of the Posttraumatic Growth Inventory. Anxiety, Stress, \& Coping, 23(2), 127 - 137.

5. Carver, C. S. (1997). You want to Measure Coping but Your Protocol is Too Long: Consider the Brief COPE. International Journal of Behavioural Medicine, 4(1), 92-100.

6. Carver, C. S., Scheier, M. F., \& Weintraub, J. K. (1989). Assessing coping strategies: A theoretically based approach. Journal of Personality and Social Psychology, 56, 267-283.

7. Christopher, M. (2004). A broader view of trauma: A bio psychosocial-evolutionary view of the role of the traumatic stress response in the emergence of pathology and/or growth. Clinical Psychology Review, 24(1), 7598.

8. Collins, R., Taylor, S., \& Skokan, L. (1990). A Better world or shattered vision: Changes in life perspectives following victimization. Social Cognition, 8, 263-265.

9. Cordova, M.J., Cunnigham, L.L.C., Carlson, C.R. \& Andrykowski, M.A. (2001). Posttraumatic growth following breast cancer: a controlled comparison study. Health Psychol, 20, 176-185.

10. Danhauer, S. C., Case, L. D., \& Tedeschi. R, G. et al (2013). Predictors of posttraumatic growth in women with breast cancer. PsychoOncol, 22(10), 2676-83.

11. de Zulueta, C. F. (2007). Mass violence and mental health: attachment and trauma. International Review of Psychiatry, 19(3), 221-233.

12. Dirik, G. \& Karanci, A.N. (2008). Variables related to posttraumatic growth in Turkish rheumatoid arthritis patients. J Clin Psychol Med Settings, 15, 193-203.

13. Dow, K.H., Ferrell, B.R., Haberman, M.R., \& Eaton, L. (1999). The meaning of quality of life in cancer survivorship. Oncol Nurs Forum, 26(3), 519-528.

14. Halcomb, E., Daly, J., Davidson, P., Elliott, D., \& Griffiths, R. (2005). Life beyond severe traumatic injury: an integrative review of the literature. Australian Critical Care Journal, 18(1), 17-18, 20-14.

15. Harvey, J., Barnett, K. \& Overstreet, A. (2004). Trauma growth and other outcomes attendant to loss. Psychological Inquiry, 15, 26-29.

16. Ho, S. M.Y., Chan, C. L.W., \& Ho, R. T. H. (2004). Posttraumatic growth in Chinese cancer survivors. Psychooncology, 13, 377-389.

17. Joseph, S., \& Linley, A.P. (2005). Positive Adjustment to Threatening Events: An Organismic Valuing Theory of Growth through Adversity. Review of General Psychology, 9(3), 262-280.

18. Keane, T. M., Marshall, A. D., \& Taft, C. T. (2006). Posttraumatic stress disorder: Etiology, epidemiology, and treatment outcome. Annual Review of Clinical Psychology, 2, 161-197.

19. Kershaw, T., Northouse, L., Kritpracha, C., Schafenacker, A., \& Mood, D. (2004). Coping strategies and quality of life in women with advanced breast cancer and their family caregivers. Psychology \& Health, 19(2), 139-155.

20. Kesimci, A., Goral, S., \& Gencoz, T. (2005). Determinants of stress related growth: Gender, Stressfulness of the event, and coping strategies. Current Psychology, 24(1), 68-75.

21. Koeing, H. G., Pargament, K. I., \& Nielsen, J. (1998). Religious coping and health status in medically ill hospitalized older adults. Journal of Nervous and Mental Diseases, 186(9), 513-521.

22. Markus, H. R., \& Kitayama, S. (1991). Culture and the self: Implications for cognition, emotion, and motivation. Psychological Review, 98, 224-253.

23. Meyer, B. (2001). Coping with severe mental illness: Relations of the Brief COPE with symptoms, functioning and well-being. Journal of Psychopathology and Behavioural Assessment, 23, 265-277. 
24. Oxman, T.E., Hegel, M.T., Hull, J.G., \& Dietrich, A.J. (2008). Problem-solving treatment and coping styles in primary care for minor depression. Journal of Consulting and Clinical Psychology, 76(6), 933-943.

25. Park, C. L, Cohen, L. H., \& Murch, R. L. (1996). Assessment and prediction of stress-related growth. Journal of Personality, 64(1), 71-105.

26. Schnider, K.R., Elhai, J.D., \& Gray, M.J. (2007). Coping style use predicts posttraumatic stress and complicated grief symptom severity among college students reporting a traumatic loss. Journal of Counselling Psychology, 54(3), 344-350.

27. Schroevers, M. J., \& Teo, I. (2008). The report of posttraumatic growth in Malaysian cancer patients: relationships with psychological distress and coping strategies. Psychooncology, 17(12), 1239-46.

28. Schroevers, M., Ranchor, A. V., \& Sanderman, R. (2006). Adjustment to cancer in the 8 years following diagnosis: A longitudinal study comparing cancer survivors with healthy individuals. Social Science \& Medicine, 63(3), 598-610.

29. Schulz, U., \& Mohamed, N. E. (2004). Turning the tide: Benefit finding after cancer surgery. Social Science \& Medicine, 59, 653-662.

30. Sears, S. R., Stanton, A. L., \& Danoff-Burg, S. (2003). The yellow brick road and the emerald city: benefit finding, positive reappraisal coping and posttraumatic growth in women with early-stage breast cancer. Health Psychol 22(5), 487-497.

31. Sears, S. R., Stanton, A. L., \& Danoff-Burg, S. (2003). The yellow brick road and the emerald city: benefit finding, positive reappraisal coping and posttraumatic growth in women with early-stage breast cancer. Health Psychol 22(5), 487-497.

32. Sheikh, A. L. (2008). Posttraumatic growth in trauma survivors: Implications for practice. Counselling Psychology Quarterly, 21(1), 85-97.

33. Siegel, K., Schrimchaw, E. W., \& Pretter, S. (2005). Stress related growth among women living with HIV/AIDS: Examination of an explanatory model. Journal of Behavioural Medicine, 28(5), 404-414.

34. Tatrow, K., \& Montgomery, G. H. (2006). Cognitive behavioral therapy techniques for distress and pain in breast cancer patients: A meta-analysis. Journal of Behavioral Medicine, 29(1), 17-27.

35. Taylor, S.E. (1983). Adjustment to threatening events: A theory of cognitive adaptation. Am Psychol, 38, 11611173.

36. Tedeschi, R. G., \& Calhoun, L. G. (1996). The posttraumatic growth inventory: measuring the positive legacy of trauma. Journal of Traumatic Stress, 9, 455-471.

37. Tedeschi, R. G., \& Calhoun, L. G. (2004). Posttraumatic growth: Conceptual foundations and empirical evidence. Psychological Inquiry, 15, 1-18.

38. Thornton, A. A., \& Perez, M. A. (2006). Post traumatic growth in prostate cancer survivors and their partners. Psycho-Oncology, 15(4), 285-296.

39. Urcuyo, K. R., Boyers, A. E., Carver, C. S., \& Antoni, M. H. (2005). Finding benefit in breast cancer: Relations with personality, coping and concurrent wellbeing. Psychology and Health, 20(2), 175-192.

40. Walsh, F. (2007). Traumatic loss and major disasters: strengthening family and community resilience. Family Process, 46(2), 207-227.

41. Weiss, T. (2004). Correlates of posttraumatic growth in married breast cancer survivors. J Social Clin Psychol, 23, 733-746.

42. Widows, M. R., Jacobsen, P. B., Booth-Jones, M., \& Fieldo, K. K. (2005). Predictors of post traumatic growth following bone marrow transplantation for cancer. Health Psychology, 24(3), 266-273.

43. Zimet, G. D., Dahlem, N. W., Zimet, S. G., \& Farley, G. K. (1988). The Multi-Dimensional Scale of Perceived Social Support. Journal of Personality Assessment, 52, 30-41.

44. Zimet, G. D., Powell, S. S., Farley, G. K., Werkman, S. \& Berkoff, K. A. (1990). Psychometric characteristics of the Multidimensional Scale of Perceived Social Support. Journal of Personality Assessment, 55, 610-17. 